\title{
Expression and clinical significance of miR-23a and MTSS1 in diffuse large B-cell lymphoma
}

\author{
MENGWEI XU and TAO XU \\ Department of Pathology, Xijing Hospital, Xi'an, Shanxi 710000, P.R. China
}

Received September 28, 2017; Accepted April 2, 2018

DOI: $10.3892 / \mathrm{ol} .2018 .8657$

\begin{abstract}
The present study investigated the expression and clinical significance of micro-ribonucleic acid-23a (miR-23a) and metastasis suppressor 1 (MTSS1) in diffuse large B-cell lymphoma (DLBCL). A total of 70 cases of tumor tissues of patients with DLBCL and 30 cases of reactive lymphoid hyperplasia tissues were collected. OCI-LY10 cell was transfected with miR-23a antisense oligonucleotide (miR-23a ASO). The expression of miR-23a and MTSS1 in tumor tissues of patients with DLBCL and reactive lymphoid hyperplasia tissues were detected by reverse transcription-quantitative polymerase chain reaction (RT-qPCR) and immunohistochemistry. Spearman's test was used for correlation analysis was also performed for their expression. The relationship of the expressions of miR-23a and MTSS1 with the pathological parameters of patients with DLBCL was further analyzed. The DLBCL OCI-LY10 cells were cultured in vitro, and gene silencing downregulated the expression of miR-23a in OCI-LY10 cells. The expression of miR-23a was studied via RT-qPCR, and the effect of downregulation of miR-23a on MTSS1 protein expression was determined by western blot analysis. Moreover, the effects of miR-23a on the proliferation, metastasis and invasion capacities of OCI-LY10 cells were observed by both methyl thiazolyl tetrazolium (MTT) assay and Transwell chamber assay. The results of RT-qPCR showed that the mRNA expression of miR-23a in DLBCL tissues was significantly higher than that of reactive hyperplasia tissues. Immunohistochemical results revealed that the positive expression rate of MTSS1 in DLBCL tissues (30.00\%) was significantly lower in comparison to reactive hyperplasia tissues $(90.00 \%)$. Correlation analysis revealed that the miR-23a expression had a significant negative correlation with MTSS1 expression $(\mathrm{r}=-0.538, \mathrm{p}=0.01)$. The expression of $\mathrm{miR}-23 \mathrm{a}$ and MTSS1 were correlated with the Ann Arbor staging,
\end{abstract}

Correspondence to: Dr Mengwei Xu, Department of Pathology, Xijing Hospital, 127 Changlexi Road, Xi'an, Shanxi 710000, P.R. China

E-mail: youbang0831@163.com

Key words: diffuse large B-cell lymphoma, micro-ribonucleic acid-23a, metastasis suppressor 1 extranodal invasion and International Prognostic Index (IPI) scores of patients $(\mathrm{p}<0.05)$. However, they had no significant correlation with the sex and age of patients $(\mathrm{p}>0.05)$. After the downregulation of miR-23a expression, the MTSS1 protein expression in OCI-LY10 cells showed a significant increase. However, the proliferation, metastasis and invasion capacities of OCI-LY10 cells were obviously decreased. In conclusion, miR-23a promoted the proliferation, invasion and metastasis of DLBCL OCI-LY10 cells through the targeted inhibition of MTSS1. The high expression of miR-23a and the low expression of MTSS1 protein could be used as reference indexes for the prognosis of DLBCL.

\section{Introduction}

Diffuse large B-cell lymphoma (DLBCL) is a subtype of non-Hodgkin lymphoma (NHL) with high incidence rate. It accounts for $30 \%$ of all malignant tumors of lymphoid tissues $(1,2)$. DLBCL is a moderately to highly malignant lymphoma, characterized by clinical heterogeneity with a high proliferation and strong metastasis. It has significant differences in immunophenotype, morphology and molecular genetics (3). As a solid tumor of the immune system $(4,5)$, the lesion sites of DLBCL are mainly in the lymph nodes, spleen, thymus, other lymphoid organs and extranodal lymphoid tissues $(6,7)$. The universally acknowledged clinical treatment means of DLBCL is the combined medication of rituximab and anthracycline drugs, with a successful treatment rate of $60-70 \%$ (8). Nevertheless, due to the large individual difference in DLBCL, some patients still have no response to the rituximab-based treatment or metastasis occurs early with a poor prognosis.

Important roles for miRs, including miR23a, have been demonstrated in earlier studies on multiple types of cancer $(8,9)$. These reports suggest the role of miR23a in tumor progression by modulating mechanisms of differentiation, proliferation, invasion and metastasis (10) Another study reported that the expression of the micro-ribonucleic acid-23a $(m i R-23 a)$ is altered in various types of cancer with diverse effects (11). These effects mainly included the orchestration of target genes important for increasing proliferation, cell differentiation and growth (12). Furthermore, miR-23a has been reported to be associated with DLBCL (13). On the other hand, metastasis suppressor 1 (MTSS1) is a known cytoskeletal-associated protein, and its role has been confirmed in certain types of 
cancer (14). It is a novel potential metastasis suppressor gene, which is also known as missing-in-metastasis (MIM). Moreover, patients diagnosed with high levels of MTSS1 transcripts had a favourable prognosis over those with reduced or lack of expression thereof (14). MTSS1 has been confirmed as a target of miR-23a in colorectal cancer, and the inhibition of MTSS1 by miR-23 results in cancer metastasis (15).

Thus, the present study investigated the expression of miR-23a and MTSS1 during DLBCL. Their effects on clinicopathological parameters of DLBCL patients were also explored. Moreover, we studied the correlation between their expression and their association with clinicopathological parameters of DLBCL. Therefore, DLBCL OCI-LY10 cells were cultured in vitro, and the relationship between miR-23a and MTSS1 expression was investigated. The study of the relationship between these parameters is crucial, as it will allow an efficient prognosis of DLBCL patients in near future.

\section{Materials and methods}

Materials. DLBCL OCI-LY10 cells (Shanghai Cell Bank, Chinese Academy of Sciences, Shanghai, China); Dulbecco's modified Eagle's medium (DMEM), fetal bovine serum (FBS), and Lipofectamine 2000 (Invitrogen: Thermo Fisher Scientific, Inc., Carlsbad, CA, USA); miR-23a antisense oligonucleotide (miR-23a ASO) (Beijing Sunbiotech Co., Ltd., Beijing, China); Transwell chamber (Corning, Inc., Corning, NY, USA); rabbit anti-human miR-23a and MTSS1 antibodies (Santa Cruz Biotechnology, Inc., Dallas, TX, USA); bicinchoninic acid (BCA) protein quantification kit and cell lysis buffer (Beyotime Institute of Biotechnology, Nantong, China), and immunohistochemical staining kit SP-9001 (Beijing Zhongshan Golden Bridge Biotechnology Co., Ltd., Beijing, China) were used in this study.

In this clinical study, 70 patients confirmed clinically and pathologically as DLBCL, and who were admitted to Xijing Hospital (Xi'an, China) from May 2012 to May 2015 were selected as the subjects of the study. The patients were aged 29-77 years with a median age of 59 years. In addition, 30 tissue specimens of patients pathologically diagnosed as reactive lymphoid hyperplasia in the same period were selected as the controls; the patients were aged 25-74 years with a median age of 57 years. There were no differences in age between the two groups. The clinicopathological data of patients were collected. The Clinical Ethics Committee of Xijing Hospital (Xi'an, China) approved this study, and patients or their families signed the informed consent.

Detection of miR-23a mRNA expression via reverse transcription-quantitative polymerase chain reaction $(R T-q P C R)$. The total RNA was extracted from the tumor tissues of lymphoma patients and reactive hyperplasia tissues using the TRIzol kit, and the qualified total RNA was selected for the reverse transcription according to the instructions of reverse transcription kit. The specific reaction conditions are as follows: Incubation at $42^{\circ} \mathrm{C}$ for $15 \mathrm{~min}$ and then at $95^{\circ} \mathrm{C}$ for $3 \mathrm{~min}$. The total RNA was cooled on ice and stored at $-80^{\circ} \mathrm{C}$ for subsequent experiments. The routine amplification was performed according to the primer sequences in Table I. With $\beta$-catenin as the internal control gene, $\mathrm{Cq}$ values were the output of the instrument. The
Table I. RT-PCR primer sequences.

\begin{tabular}{lll}
\hline Gene & & \multicolumn{2}{c}{ Primer sequence } \\
\hline$U 6$ & F & 5'-GCTTCGGCAGCACATATACTAAAAT-3' \\
& R & 5'-CGCTTCACGAATTTGCGTGTCAT-3' \\
$m i R-23 a$ & F & 5 5'-ATCACATTGCCAGGGATTTCC-3' \\
& R & 5'-CCAGTGCAGGGTCCGAGGT-3'
\end{tabular}

miR-23a, micro-ribonucleic acid-23a; F, forward; R, reverse.

relative expression level of miR-23a mRNA was calculated using the $2^{-\Delta \Delta \mathrm{Cq}}$ method.

Detection of the expression of MTSS1 protein in pathological tissues via immunohistochemistry. After surgical resection, tumor tissues were fixed with formaldehyde, followed by conventional paraffin embedding and tissue cutting. Immunohistochemical staining was conducted according to the instructions of the SP-9001 kit, followed by dewaxing and hydration of paraffin sections. After the sections were treated with $3 \% \mathrm{H}_{2} \mathrm{O}_{2}$ for 10 min to inactivate the endogenous peroxidase, they were placed in citric acid buffer for antigen retrieval using the microwave oven, and added with mouse anti-human MTSS1 monoclonal antibody (1:100; cat. no. sc-101204; Santa Cruz Biotechnology, Inc.). Phosphate-buffered saline (PBS) replaced the primary antibody as the negative control at $4^{\circ} \mathrm{C}$ overnight. Sections were washed with PBS and added with biotin-labeled goat anti-mouse secondary polyclonal antibody (1:500, cat. no. sc-2039; Santa Cruz Biotechnology, Inc.) for incubation for $15 \mathrm{~min}$, followed by washing with PBS, color development via diaminobenzidine (DAB) in the dark, hematoxylin re-staining and sealing via neutral gum.

Optical microscope (x400) was used for evaluation of MTSS1 staining and six visual fields were randomly selected. The score was based on the percentage of positive cells and the staining depth; positive cells $>75 \%$ : 4 points; $51-75 \%$ : 3 points; 11-50\%: 2 points; $\leq 10 \%$ : 1 point; no positive cells: 0 point. Then according to the staining depth, dark brown: 3 points; brown yellow: 2 points; faint yellow: 1 point; no color: 0 point. Both results were multiplied. A product of $>3$ points was considered positive expression, while $\leq 2$ points was negative expression. The scores were statistically analyzed using SPSS 19.0 (SPSS, Inc., Chicago, IL, USA).

Expression of miR-23a and MTSS1 in DLBCL tissues and their correlation with pathological parameters. According to the expression levels of miR-23a and MTSS1 in DLBCL tissues, 70 cases of DLBCL tissues were divided into high- and low-expression miR-23a groups and positive- and negative-expression MTSS1 groups. According to the clinical data of patients, the relationship of miR-23a and MTSS1 expression with the pathological parameters of patients was analyzed using the Chi-square test.

OCI-LY10 cell culture and miR-23a ASO transfection. DLBCL OCI-LY10 cells were cultured in DMEM culture solution containing $10 \% \mathrm{FBS}$ in an incubator with $5 \% \mathrm{CO}_{2}$ at 
$37^{\circ} \mathrm{C}$. After the cells were fully grown, they were digested and collected for subsequent experiments.

In the experiment, cells were divided into the negative control group [control small interfering RNA (siRNA)] and ASO group (miR-23a ASO). The cells in logarithmic growth phase were collected and inoculated into a sterile 6 -well plate $\left(4 \times 10^{5} /\right.$ well) for incubation in an incubator with $5 \% \mathrm{CO}_{2}$ at $37^{\circ} \mathrm{C}$. After $24 \mathrm{~h}$, according to instructions of the Lipofectamine ${ }^{\mathrm{TM}} 2000 \mathrm{kit}, 500 \mu \mathrm{l}$ transfection complex containing miR-23a ASO/Ctrl siRNA and 1,500 $\mu$ l serum-free DMEM culture solution were added into each well. Each group was placed in an incubator with $5 \% \mathrm{CO}_{2}$ at $37^{\circ} \mathrm{C}$ for $48 \mathrm{~h}$. The cells were then digested and collected for subsequent experiments.

Verification of interference effect of $m i R-23$ a siRNA on $m R N A$ via $R T-q P C R$. After cell transfection according to the steps followed in OCI-LY10 cell culture and miR-23a ASO transfection', the mRNA expression after interference with control siRNA and miR-23a ASO was detected based on the steps in 'Detection of expression of MTSS1 protein in pathological tissues via immunohistochemistry'.

Detection of MTSS1 protein expression via western blot analysis. After transfection, the DLBCL OCI-LY10 cells were resuspended using the cell lysis buffer, and cleaved on ice for $30 \mathrm{~min}$, followed by centrifugation at $10,680 \mathrm{x} \mathrm{g}$ at $4^{\circ} \mathrm{C}$ for $15 \mathrm{~min}$. The supernatant was carefully absorbed as the total protein. After protein quantification using the BAC protein quantification kit, the loading buffer was added, $60 \mu \mathrm{g}$ proteins in each group were taken for $10 \%$ sodium dodecyl sulfate-polyacrylamide gel electrophoresis and separation, and the protein was transferred onto the polyvinylidene fluoride (PVDF) membrane with wet method. The membrane was sealed using Tris-buffered saline (TBS) containing 5\% skimmed milk at room temperature for $1 \mathrm{~h}$, and mouse anti-human MTSS1 and glyceraldehyde-3-phosphate dehydrogenase (GADPH) primary monoclonal antibodies (diluted at 1:1,000; cat. nos. sc-101204, sc-59540; Santa Cruz Biotechnology, Inc.) were added dropwise for incubation at $4^{\circ} \mathrm{C}$ overnight. The next day, the membrane was washed with Tris-buffered saline with Tween-20 (TBST) three times (15 min/time). Then goat anti-mouse horseradish peroxidase (HRP)-labeled secondary polyclonal antibody (diluted at 1:2,000; cat. no. sc-2005; Santa Cruz Biotechnology, Inc.) was added for incubation at room temperature for $1 \mathrm{~h}$, followed by washing with TBST, luminous reaction using electrochemiluminescence (ECL) kit, image scanning and analysis, and gray scale analysis with GADPH as the internal reference.

Detection of the effect of miR-23a ASO interference on cell proliferation capacity via methyl thiazolyl tetrazolium (MTT) assay. In the experiment, the cells were divided into negative control siRNA and miR-23a ASO. After $48 \mathrm{~h}$, the cells (DLBCL OCI-LY10) were collected and inoculated onto the 96-well plate at a density of $1 \times 10^{3} / 100 \mu \mathrm{l}$. After $48 \mathrm{~h}, 5 \mathrm{~g} / \mathrm{l}$ MTT solution was added into each well for incubation for $4 \mathrm{~h}$. The supernatant was removed from the wells, $100 \mu \mathrm{l}$ dimethyl sulfoxide (DMSO) solution was added into each well and agitated for $10 \mathrm{~min}$. The optical density of each well at

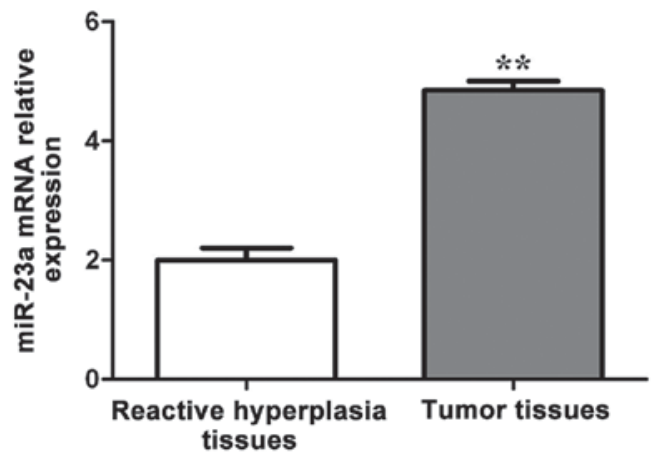

Figure 1. Detection of miR-23a mRNA expression in reactive hyperplasia and tumor tissues via RT-PCR; ${ }^{*}$ p $<0.01$. miR-23a, micro-ribonucleic acid-23a.

the wavelength of $490 \mathrm{~nm}$ was detected using a microplate reader (Thermo Fisher Scientific, Inc., Waltham, MA, USA), and the cell growth curve was drawn.

Detection of the effect of miR-23a ASO interference on cell metastasis capacity via Transwell assay. At $48 \mathrm{~h}$ after transfection (DLBCL OCI-LY10), the cells were collected to detect the metastasis capacity using Transwell chamber. The cells were prepared into the $4 \times 10^{5} / \mathrm{ml}$ cell suspension using the culture solution. Cell suspension $(100 \mu \mathrm{l})$ was added into the upper Transwell chambers coated with Matrigel, while $500 \mu \mathrm{l}$ culture solution was added into the lower chamber for incubation in an incubator for $24 \mathrm{~h}$. Then the chamber was removed and fixed via formalin for $2 \mathrm{~min}$, followed by $0.1 \%$ crystal violet staining for $15 \mathrm{~min}$. The visual fields were randomly selected under a microscope (Nikon Corp., Tokyo, Japan) for photography, counting and analysis.

Statistical analysis. Statistical Product and Service (SPSS) 17.0 software (IBM Corp., Armonk, New York, USA) was used for data processing in the present study. Measurement data were presented as mean \pm standard deviation, and the ANOVA test was used for intergroup comparison and the post hoc test was SNK test. The Chi-square test was used for intergroup comparison of enumeration data. Spearman's test was used for correlation analysis. $\mathrm{P} \leq 0.05$ indicated that the difference was statistically significant.

\section{Results}

miR-23a mRNA expression in reactive hyperplasia and tumor tissues. As shown in Fig. 1, the miR-23a mRNA expression in DLBCL tissues was significantly higher than that in reactive hyperplasia tissues, and the difference was statistically significant $(\mathrm{p}<0.01)$.

According to the average relative expression level of miR-23a mRNA in DLBCL tissues, 70 patients were divided into the high-expression $(n=56)$ and low-expression $(n=14)$ miR-23a groups.

Detection of MTSS1 protein expression in pathological tissues via immunohistochemical assay. The results of immunohistochemical detection showed that positive immunohistochemical staining for MTSS1 appeared brown yellow. MTSS1 proteins 


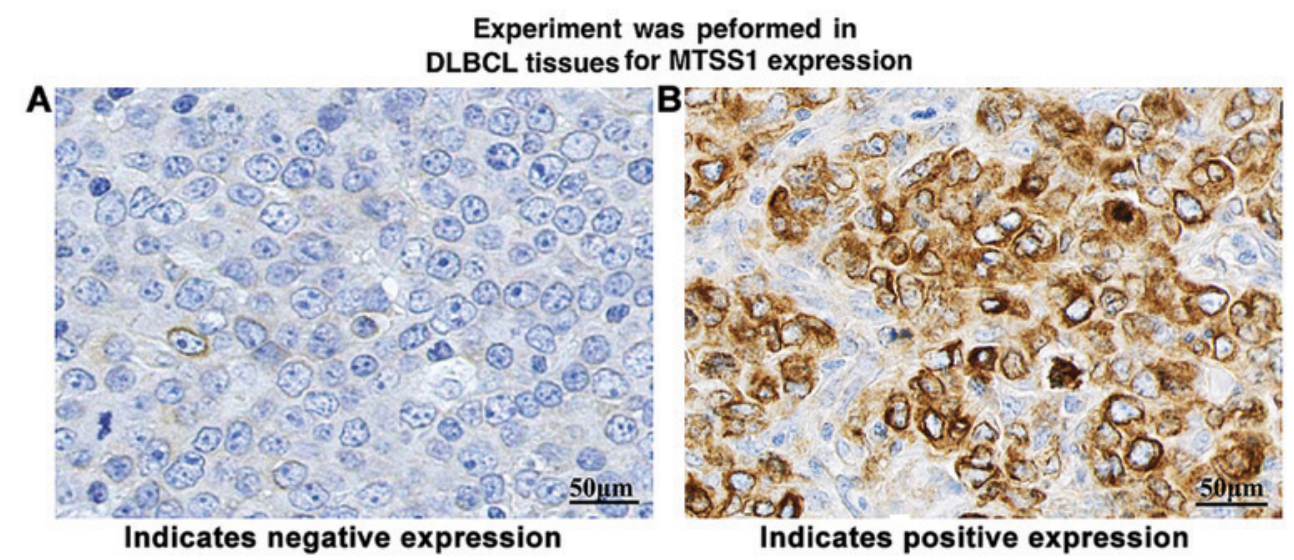

Figure 2. Detection of MTSS1 protein expression in pathological tissues via immunohistochemical assay (x400). (A) Negative expression; (B) positive expression. MTSS1, metastasis suppressor 1.

Table II. Correlation between miR-23a and MTSS1 protein expression in DLBCL tissues.

\begin{tabular}{lrrrrr}
\hline & \multicolumn{2}{c}{ MTSS1 } & & \\
\cline { 2 - 3 } miR-23a & Positive & Negative & r & P-value \\
\hline High expression & 13 & 43 & -0.538 & $<0.01$ \\
Low expression & 8 & 6 & & \\
\hline
\end{tabular}

miR-23a, micro-ribonucleic acid-23a; MTSS1, metastasis suppressor 1; DLBCL, diffuse large B-cell lymphoma.

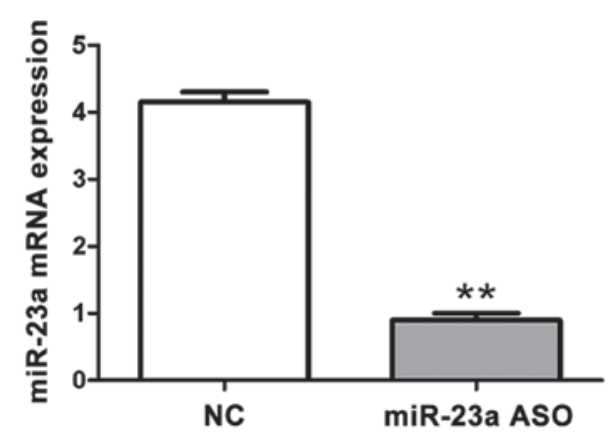

Figure 3. Verification of interference effect of miR-23a ASO on mRNA via RT-qPCR; Compared pith that in control group, the miR-23a expression in ASO group is decreased. ${ }^{* *} \mathrm{p}<0.01$. miR-23a ASO, miR-23a antisense oligonucleotide; RT-qPCR, quantitative reverse transcription-polymerase chain reaction.

were mainly located in the cytoplasm, showing diffuse distribution (Fig. 2). The positive expression rates of MTSS1 in DLBCL tissues and reactive hyperplasia tissues were $30 \%$ $(21 / 70)$ and $90 \%$ (27/30), respectively, and the difference was statistically significant $(\mathrm{p}<0.01)$ (Table II).

Correlation between miR-23a and MTSS1 protein expression in DLBCL tissues. In the 70 cases of DLBCL tissues, there were 6 cases of miR-23a protein positive $(+)$ and MTSS1 protein (+), 15 cases of miR-23a protein (-) and MTSS1 protein $(-), 41$ cases of miR-23a protein (+) and MTSS1 protein (-), and

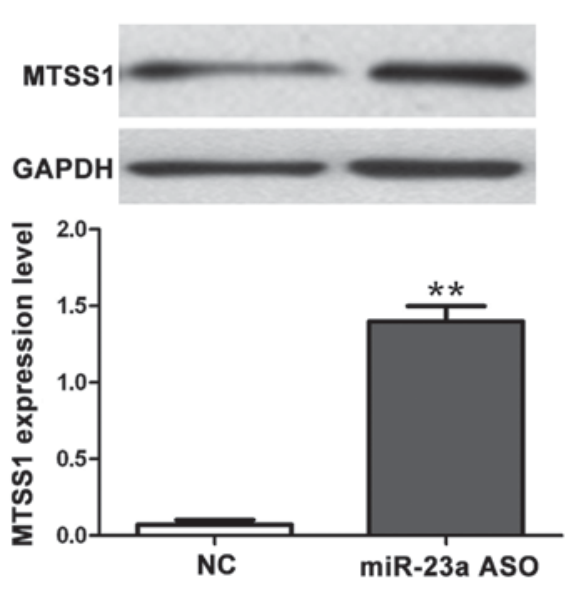

Figure 4. Detection of effect of miR-23a ASO interference in miR-23a on MTSS1 protein expression via western blotting. Compared with that in control group, the MTSS1 protein expression is increased; ${ }^{* *} \mathrm{p}<0.01$. miR-23a ASO, miR-23a antisense oligonucleotide; miR-23a, micro-ribonucleic acid-23a; MTSS1, metastasis suppressor 1.

8 cases of miR-23a protein (-) and MTSS1 protein (+). The correlation between miR-23a and MTSS1 protein expression in DLBCL tissues was analyzed via Spearman's test. The results revealed that there was a negative correlation between them (correlation coefficient $\mathrm{r}=-0.538$ ), and the correlation was statistically significant $(\mathrm{p}<0.01)$ (Table II).

Relationship of miR-23a and MTSS1 expression with clinicopathological parameters of DLBCL. Analysis of the relationship of miR-23a and MTSS1 expression with clinicopathological parameters of DLBCL patients showed that the high expression of miR-23a and negative expression of MTSS1 were associated with Ann Arbor staging, extranodal invasion and International Prognostic Index (IPI) score ( $<<0.01)$ (Table III).

Verification of interference effect of miR-23a ASO on mRNA via $R T-q P C R$. As shown in Fig. 3, RT-qPCR was performed to confirm the interference effect of miR-23a ASO on mRNA after OCI-LY10 cell transfection. The results showed that mRNA content in the miR-23a ASO group was significantly lower than that in the negative control group, and the difference was statistically significant $(\mathrm{p}<0.01)$. 
Table III. Relationship of miR-23a and MTSS1 expression with clinicopathological parameters of DLBCL.

\begin{tabular}{|c|c|c|c|c|c|c|c|}
\hline \multirow[b]{2}{*}{ Clinical data } & \multirow[b]{2}{*}{ No. } & \multicolumn{3}{|c|}{ miR-23a } & \multicolumn{3}{|c|}{ MTSS1 } \\
\hline & & High expression $(\mathrm{n}, \%)$ & $\chi^{2}$ & P-value & Negative $(\mathrm{n}, \%)$ & $\chi^{2}$ & P-value \\
\hline \multicolumn{8}{|l|}{ Sex } \\
\hline Male & 34 & $27(79.41)$ & 0.01 & $>0.05$ & $26(76.47)$ & 1.32 & $>0.05$ \\
\hline Female & 36 & $29(80.56)$ & & & $23(63.89)$ & & \\
\hline \multicolumn{8}{|l|}{ Age (years) } \\
\hline$\geq 60$ & 37 & $31(83.78)$ & 0.70 & $>0.05$ & $25(67.57)$ & 0.22 & $>0.05$ \\
\hline$<60$ & 33 & $25(75.76)$ & & & $24(72.73)$ & & \\
\hline \multicolumn{8}{|c|}{ Ann Arbor staging } \\
\hline I-II & 29 & $19(65.52)$ & 6.49 & $<0.05$ & $14(48.28)$ & 11.13 & $<0.01$ \\
\hline III-IV & 41 & $37(90.24)$ & & & $35(85.37)$ & & \\
\hline \multicolumn{8}{|c|}{ Extranodal invasion } \\
\hline Yes & 43 & $39(90.70)$ & 7.97 & $<0.01$ & $37(86.05)$ & 13.67 & $<0.01$ \\
\hline No & 27 & $17(62.96)$ & & & $12(44.44)$ & & \\
\hline \multicolumn{8}{|l|}{ IPI score } \\
\hline $0-2$ & 39 & $27(69.23)$ & 6.38 & $<0.05$ & $22(56.41)$ & 7.74 & $<0.01$ \\
\hline $3-5$ & 31 & $29(93.55)$ & & & $27(87.70)$ & & \\
\hline
\end{tabular}

miR-23a, micro-ribonucleic acid-23a; MTSS1, metastasis suppressor 1; DLBCL, diffuse large B-cell lymphoma; IPI, International Prognostic Index.

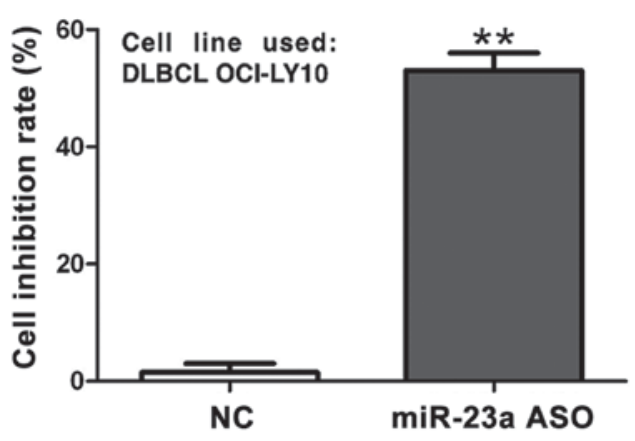

Figure 5. Detection of interference effect of miR-23a ASO on the cell proliferation capacity via MTT assay. Compared with that in control group, the cell proliferation inhibition rate in miR-23a ASO interference group is significantly increased at $48 \mathrm{~h} ;{ }^{* *} \mathrm{p}<0.01$. miR-23a ASO, miR-23a antisense oligonucleotide; MTT, methyl thiazolyl tetrazolium.

Detection of the effect of miR-23a ASO interference in miR-23a on MTSS1 protein expression via western blot analysis. The effect of RNA interference (RNAi) in miR-23a on MTSS1 protein expression was detected via western blot analysis. Results showed that compared with the control group, miR-23a expression in ASO group was decreased (Fig. 3), but the MTSS1 protein expression was increased $(\mathrm{p}<0.01)$, indicating that miR-23a can negatively regulate the expression of MTSS1 (Fig. 4).

Detection of interference effect of miR-23a ASO on cell proliferation capacity via MTT assay. MTT assay showed that compared with that in control group, the cell proliferation inhibition rate in miR-23a ASO interference group was

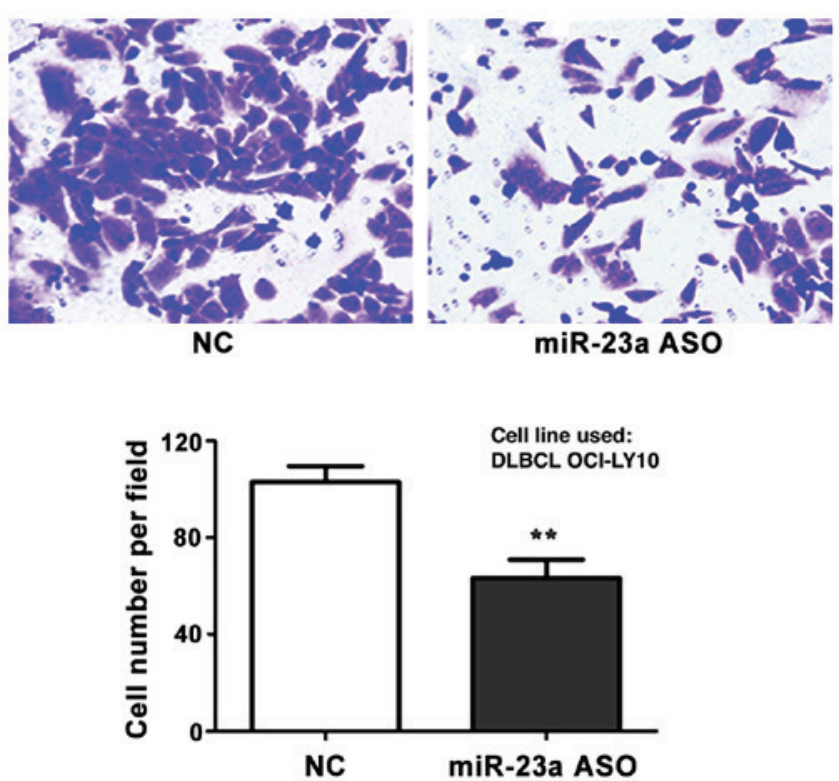

Figure 6. Detection of interference effect of miR-23a ASO on cell metastasis capacity via Transwell assay. The number of metastatic cells in ASO group is significantly decreased compared with that in control group; ${ }^{* *} \mathrm{p}<0.01$. miR-23a ASO, miR-23a antisense oligonucleotide.

significantly decreased $(\mathrm{p}<0.01)$, while the inhibition rate increased to $53 \%$ at $48 \mathrm{~h}$ after transfection (Fig. 5).

Detection of interference effect of miR-23a ASO on cell metastasis capacity via Transwell assay. The interference effect of miR-23a ASO on cell metastasis capacity was investigated via Transwell metastasis assay. The results revealed that the 
number of metastatic cells in ASO group was significantly decreased in comparison to control group ( $\mathrm{p}<0.01)$ (Fig. 6).

\section{Discussion}

The mechanism involved in the tumor occurrence and progression is complex, and includes, not only the imbalance among a variety of oncogenes and tumor suppressor genes, but it also changes in different signal pathways. The miRNA function has attracted significant attention in recent years. miRNAs have multiple important roles in different life processes, such as tissue embryo development, cell proliferation, differentiation and apoptosis and immune regulation (16). The discovery of miRNA physiological function provides a new perspective for the research on tumors.

miRNA is an endogenous small-molecular RNA with non-coding properties, of 19-24 nucleotides in length and plays an important role as a signal molecule in cell proliferation, differentiation, apoptosis and other physiological processes (17). The expression of miRNAs regulates cell proliferation and differentiation in the physiological state, and is related to the occurrence and progression of tumor during abnormal conditions. The action of miRNAs binds to the target gene, thereby negatively regulates the target gene expression at the post-transcriptional level (18). It has also been reported that $m i R-23$ gene is involved in the cell growth and development, such as proliferation, apoptosis and mutation. In terms of cell metabolism, it was reported (19) that $\mathrm{N}$-acetylglucosyltransferase III, as the target gene of miR-23a, played a regulatory role in the $\mathrm{N}$-glycan synthesis process (20). Recent findings have shown that the occurrence and development of human tumors have very close relationships with miRNA; there are special miRNAs in many cancer cells, and these miRNAs regulate the cancer cell proliferation, apoptosis and invasion (21). In the tumor research field, miR-23a has become a new concern, which plays a role as oncogene in most pathways, and participates in tumor occurrence and metastasis in the respiratory, digestive and reproductive system (22). MTSS1 has confirmed ability to inhibit tumor metastasis (23), and the MTSS1-encoded intracellular proteins play important roles in the recombination of actin cytoskeleton. Therefore, it is generally believed that the protein encoded by MTSS1 gene is related to tumor cell proliferation, invasion and metastasis. Lee et al (24) found that MTSS1 gene expression was increased in early malignant bladder tumor cell lines, but it was not expressed or had low expression in the cases of prostate cancer or breast cancer cell metastasis. Thus, MTSSI gene may inhibit tumor cell metastasis.

To investigate the expressions of miR-23a and MTSS1 in DLBCL, their effects on clinicopathological parameters of patients with DLBCL were explored. The proliferation and metastasis of DLBCL cells, miR-23a/MTSS1 expressions in DLBCL tissues and reactive lymphoid hyperplasia tissues were detected using RT-qPCR as well as immunohistochemistry, respectively. The results showed that miR-23a mRNA expression in DLBCL tissues was significantly higher than that in reactive hyperplasia tissues. The immunohistochemical results revealed that the positive expression rate of MTSS1 in DLBCL tissues (30\%) was significantly lower than that of reactive hyperplasia tissues $(90 \%)$. In addition, the correlation analysis showed that the miR-23a expression had a significantly negative correlation with MTSS1 expression ( $\mathrm{r}=-0.538, \mathrm{p}<0.01)$. Moreover, the expression of miR-23a and MTSS1 were correlated with the Ann Arbor staging, extranodal invasion and IPI score of patients. However, there was no significant correlation with the sex and age of patients. In order to further confirm the effects of miR-23a on MTSS1 expression, cell proliferation and invasion, DLBCL OCI-LY10 cells were cultured in vitro. The expression of miR-23a was silenced using the RNAi technique. The results showed that miR-23a could promote the proliferation and metastasis of OCI-LY10 cells by negative regulation of MTSS1 expression. The results were consistent with in vivo study observations. Similar to the results of the present study, a recent study showed that $m i R-23$ gene had the function of promoting the proliferation as well as metastasis of gastric cancer cells (25). Furthermore, the target gene of miR-23a, MTSS, could inhibit the expression of MTSS, leading to rapid proliferation and metastasis of colon cancer cells (26). Moreover, the expression of miR-23a in bladder tumor cells was significantly higher in comparison to control group. This again demonstrated that $m i R-23 a$ gene played an important role in the progression of bladder cancer (27). In addition, some studies have also proved that the overexpression of MTSS1 in breast cancer cell lines could obviously inhibit cancer cell proliferation, invasion and adhesion. The inhibition was more significant when the MTSSI gene was knocked out (28). The study the prognostic significance of both miR-23a and MTSS1 is to be examined in great detail in our future studies by the comparative analyses of expression levels of both miR23a as well as MTSS1 at DLBCL onset, remission and relapse.

In conclusion, miR-23a and MTSS1 are abnormally expressed in tumor tissues of patients with DLBCL and their abnormal expression is related to the Ann Arbor staging, extranodal invasion and IPI score. Moreover, miR-23a could affect the proliferation and metastasis of DLBCL cells via negative regulation of MTSS1 expression.

\section{Acknowledgements}

Not applicable.

\section{Funding}

No funding was received.

\section{Availability of data and materials}

The datasets used and/or analyzed during the current study are available from the corresponding author on reasonable request.

\section{Authors' contributions}

MX wrote the manuscript. TX and MX were responsible for IHC, western blot analysis and PCR. Both authors read and approved the final manuscript.

\section{Ethics approval and consent to participate}

The Clinical Ethics Committee of Xijing Hospital (Xi'an, China) approved this study, and patients or their families signed the informed consent. 


\section{Consent for publication}

Not applicable.

\section{Competing interests}

The authors declare that they have no competing interests.

\section{References}

1. Vaidya R and Witzig TE: Prognostic factors for diffuse large B-cell lymphoma in the $\mathrm{R}(\mathrm{X}) \mathrm{CHOP}$ era. Ann Oncol 25: 2124-2133, 2014.

2. Smith A, Howell D, Patmore R, Jack A and Roman E: Incidence of haematological malignancy by sub-type: A report from the Haematological Malignancy Research Network. Br J Cancer 105 1684-1692, 2011

3. Hans CP, Weisenburger DD, Greiner TC, Gascoyne RD, Delabie J, Ott G, Müller-Hermelink HK, Campo E, Braziel RM, Jaffe ES, et al: Confirmation of the molecular classification of diffuse large B-cell lymphoma by immunohistochemistry using a tissue microarray. Blood 103: 275-282, 2004.

4. Shankland KR, Armitage JO and Hancock BW: Non-Hodgkin lymphoma. Lancet 380: 848-857, 2012.

5. Ghielmini M, Vitolo U, Kimby E, Montoto S, Walewski J, Pfreundschuh M, Federico M, Hoskin P, McNamara C, CaligarisCappio F, et al; Panel Members of the 1st ESMO Consensus Conference on Malignant Lymphoma: ESMO Guidelines consensus conference on malignant lymphoma 2011 part 1 : Diffuse large B-cell lymphoma (DLBCL), follicular lymphoma (FL) and chronic lymphocytic leukemia (CLL). Ann Oncol 24: 561-576, 2013

6. Essadi I, Ismaili N, Tazi E, Elmajjaoui S, Saidi A, Ichou M and Errihani H: Primary lymphoma of the head and neck: Two case reports and review of the literature. Cases J 1: 426, 2008.

7. PDQ Adult Treatment Editorial Board: Adult Non-Hodgkin Lymphoma Treatment (PDQ): Health Professional Version. PDQ Cancer Information Summaries [Internet], National Cancer Institute (US), Bethesda, 2002.

8. Dogan A, Bagdi E, Munson P and Isaacson PG: CD10 and BCL-6 expression in paraffin sections of normal lymphoid tissue and B-cell lymphomas. Am J Surg Pathol 24: 846-852, 2000

9. Chhabra R, Dubey R and Saini N: Cooperative and individualistic functions of the microRNAs in the miR-23a 27a 24-2 cluster and its implication in human diseases. Mol Cancer 9: 232, 2010.

10. Chhabra R, Adlakha YK, Hariharan M, Scaria V and Saini N: Upregulation of miR-23a-27a-24-2 cluster induces caspase-dependent and -independent apoptosis in human embryonic kidney cells. PLoS One 4: e5848, 2009.

11. Kong KY, Owens KS, Rogers JH, Mullenix J, Velu CS, Grimes HL and Dahl R: MIR-23A microRNA cluster inhibits B-cell development. Exp Hematol 38: 629-640. e1, 2010.

12. Schetter AJ, Nguyen GH, Bowman ED, Mathé EA, Yuen ST, Hawkes JE, Croce CM, Leung SY and Harris CC: Association of inflammation-related and microRNA gene expression with cancer-specific mortality of colon adenocarcinoma. Clin Cancer Res 15: 5878-5887, 2009
13. Wang WL, Yang C, Han XL, Wang R, Huang Y, Zi YM and Li JD: MicroRNA-23a expression in paraffin-embedded specimen correlates with overall survival of diffuse large B-cell lymphoma. Med Oncol 31: 919, 2014.

14. Du P, Ye L, Li H, Yang Y and Jiang WG: The tumour suppressive role of metastasis suppressor-1, MTSS1, in human kidney cancer, a possible connection with the SHH pathway. J Exp Ther Oncol 10: 91-99, 2012.

15. Jahid S, Sun J, Edwards RA, Dizon D, Panarelli NC, Milsom JW Sikandar SS, Gümüs ZH and Lipkin SM: miR-23a promotes the transition from indolent to invasive colorectal cancer. Cancer Discov 2: 540-553, 2012.

16. Brennecke J, Hipfner DR, Stark A, Russell RB and Cohen SM bantam encodes a developmentally regulated microRNA that controls cell proliferation and regulates the proapoptotic gene hid in Drosophila. Cell 113: 25-36, 2003.

17. Blower PE, Chung JH, Verducci JS, Lin S, Park JK, Dai Z, Liu CG, Schmittgen TD, Reinhold WC, Croce CM, et al: MicroRNAs modulate the chemosensitivity of tumor cells. Mol Cancer Ther 7: 1-9, 2008.

18. Du T and Zamore PD: microPrimer: The biogenesis and function of microRNA. Development 132: 4645-4652, 2005.

19. Bushati N and Cohen SM: microRNA functions. Annu Rev Cell Dev Biol 23: 175-205, 2007.

20. Rao SA, Santosh V and Somasundaram K: Genome-wide expression profiling identifies deregulated miRNAs in malignant astrocytoma. Mod Pathol 23: 1404-1417, 2010.

21. Deng D, Wang L, Chen Y, Li B, Xue L, Shao N, Wang Q, Xia X, Yang $Y$ and Zhi F: MicroRNA-124-3p regulates cell proliferation, invasion, apoptosis, and bioenergetics by targetingPIM1 in astrocytoma. Cancer Sci 107: 899-907, 2016.

22. Hu X, Chen D, Cui Y, Li Z and Huang J: Targeting microRNA-23a to inhibit glioma cell invasion via HOXD10. Sci Rep 3: 3423 , 2013.

23. Lee SH, Kerff F, Chereau D, Ferron F, Klug A and Dominguez R: Structural basis for the actin-binding function of missing-in-metastasis. Structure 15: 145-155, 2007.

24. Lee YG, Macoska JA, Korenchuk S and Pienta KJ: MIM, a potential metastasis suppressor gene in bladder cancer. Neoplasia 4: 291-294, 2002.

25. Li X, Zhang Y, Zhang H, Liu X, Gong T, Li M, Sun L, Ji G, Shi Y, Han Z, et al: miRNA-223 promotes gastric cancer invasion and metastasis by targeting tumor suppressor EPB41L3. Mol Cancer Res 9: 824-833, 2011.

26. Wang Z, Wei W and Sarkar FH: miR-23a, a critical regulator of 'migR'ation and metastasis in colorectal cancer. Cancer Discov 2: 489-491, 2012.

27. Gottardo F, Liu CG, Ferracin M, Calin GA, Fassan M, Bassi P, Sevignani C, Byrne D, Negrini M, Pagano F, et al: Micro-RNA profiling in kidney and bladder cancers. Urol Oncol 25: 387-392, 2007.

28. Parr C and Jiang WG: Metastasis suppressor 1 (MTSS1) demonstrates prognostic value and anti-metastatic properties in breast cancer. Eur J Cancer 45: 1673-1683, 2009. 